\title{
LA LEY CATALANA DE CONSULTAS POPULARES DE 2014
}

ÁNGEL LUIS ALONSO DE ANTONIO 
SUMARIO

I. INTRODUCCIÓN. II. ANTECEDENTES. III. CONTENIDO 


\title{
LA LEY CATALANA DE CONSULTAS POPULARES DE 2014
}

\author{
ÁNGEL LUIS ALONSO DE ANTONIO ${ }^{1}$ \\ Profesor Titular de Derecho Constitucional \\ Universidad Complutense de Madrid
}

\section{INTRODUCCIÓN}

El Parlament de Catalunya aprobó el 19 de septiembre de 2014 la Ley 10/2014, de 26 de septiembre, de consultas populares no referendarias y otras formas de participación ciudadana, cuyos artículos 3.3 en sus dos primeras frases y 16.4 a 9 fueron declarados inconstitucionales y nulos por STC 31/2015, de 25 de febrero. Con independencia de su valoración, positiva o negativa, tal vez sea la ley más importante aprobada en España en mucho tiempo porque no es solo un mero y aséptico desarrollo del artículo 122 del Estatuto de Autonomía de Cataluña (EAC) sino que su génesis y algunos acontecimientos posteriores a su aprobación demuestran que era una norma pensada, también, como instrumento jurídico para realizar una consulta que replanteara el status quo de Cataluña. Se dijo por ello en su momento, acertadamente, que «a nadie se le escapa que sin el 9-N en perspectiva difícilmente esta herramienta de regeneración democrática habría visto la luz con tanta celeridad ${ }^{2}$ ya que, como apuntó Fossas, "políticos y comentaristas se afanan en anunciarnos que se acerca la hora decisiva de Cataluña, pues ya ha empezado la cuenta atrás para el 9 de noviembre y nadie sabe qué nos espera» ${ }^{3}$.

La realidad confirmó estas palabras publicándose el Decreto 129/2014, de 27 de septiembre, de convocatoria de la consulta popular no referendaria sobre el futuro político de Cataluña. Su impugnación ante el Tribunal Constitucional por el Gobierno de España, resuelta por STC 32/2015, de 25 de febrero, declarando inconstitucio-

${ }^{1}$ Profesor Titular de Derecho Constitucional. Departamento de Derecho Constitucional. Facultad de Derecho. Universidad Complutense de Madrid. Ciudad Universitaria, s/n. 28040 Madrid. Email: anlualan@ucm.es

${ }^{2}$ La ley de consultas y el desafío del 9-N, Editorial de El Periódico, 19 de septiembre de 2014, pág. 10.

3 Fossas, Enric, «Consulta 9-N: suspensión sin suspense», en El País, 19 de septiembre de 2014, pág. 37. 
nal dicho Decreto, hizo que la misma se transformase en un proceso participativo para algunos asimilado a una mera expresión de opinión ciudadana.

El propósito del Govern de convocar una consulta sobre el futuro de los catalanes requería rodearla de las garantías de legalidad imprescindibles para que pudiera celebrarse y fuera admitida por la comunidad internacional. El criterio del Govern y de los partidos que apoyaron parlamentariamente la aprobación de la Ley era que el texto cumplía el stándar mínimo de legitimidad democrática y en consecuencia podía utilizarse para convocar una consulta sobre el futuro de Cataluña. Intentaban suplir así la carencia de base legal ante la imposibilidad de convocar un auténtico referéndum, competencia reservada al Estado (art. 149.1.32. ${ }^{a} \mathrm{CE}$ ). La trascendencia, pues, de la Ley es incuestionable así como la de la STC 31/2015, de 25 de febrero, aunque su contenido no debe sorprender por la jurisprudencia del Tribunal Constitucional relativa al referéndum y la interpretación estricta de la STC 31/2010, de 28 de junio. FJ 69 sobre el alcance del art. 122 EAC.

\section{ANTECEDENTES}

Esta Ley no es el único texto, publicado o non nato, sobre consultas populares en la reciente historia catalana porque hay dos antecedentes implicando, según el Parlament de Catalunya en su escrito de alegaciones ante el Tribunal Constitucional en el recurso de inconstitucionalidad presentado por el Presidente del Gobierno contra esta Ley, que «el escenario de conjunto que representan la Ley 2/2010 y la reciente Ley 10/2014 no puede ser otro que el de reafirmar la voluntad y coherencia del legislador a la hora de afrontar el tratamiento legal de la participación ciudadana de forma global y diferenciando claramente el régimen jurídico específico del referéndum (Ley 4/2010) del de las consultas populares no referendarias (Ley 10/2014)» ${ }^{4}$.

Uno de esos antecedentes se aprobó, la Ley 4/2010, de 17 de marzo, de consultas populares por vía de referéndum ${ }^{5}$, declarada inconstitucional en gran parte por STC $51 / 2017$, de 10 de mayo. Su constitucionalidad era dudosa porque «supera ampliamente el ámbito de las competencias de la Generalitat» ${ }^{6}$, no respetaba la exclusividad competencial del Estado para autorizar la convocatoria de consultas populares por vía

${ }^{4}$ Alegación II, 3, pág. 18. Véase el texto en http://www.parlament.cat/actualitat/actes/ALLEGACIONS\%20LLEI\%20CONSULTES.pdf.

5 Sobre esa Ley, vid. Ausàs, Jordi, Catalunya podrá convocar referéndums: presentaciò de l'Avantprojecte de llei de consultes populars per via de referéndum, Generalitat de Catalunya, Barcelona, 2009; MARTín I Alonso, Gerard, «La Llei 4/2010, del 17 de març, de consultes populars per via de referéndum, i les consultes referendàries d’àmbit de Catalunya: règim jurídic i posible aplicación», en Activitat parlamentària, núm. 25, vol. 1, 2012, pp. 24-35.

6 Carreras, Francesc de, «¿Puede celebrarse un referéndum en Cataluña?», en El Cronista del Estado Social y Democrático de Derecho. Cataluña como problema, núm. 42, febrero 2014, pág. 31. 
de referéndum (art. 149.1.32. ${ }^{a} \mathrm{CE}$ ) ni respondía a la jurisprudencia del Tribunal Constitucional sobre consultas populares y referéndum por lo que ya se apuntó en su momento, por ejemplo, que «no parece que deje precisamente mucho margen a la referida Ley del Parlament catalán sobre consultas populares por vía de referéndum, en particular en lo que al referéndum autonómico se refiere» ${ }^{7}$.

Efectivamente, la Ley 4/2010, de 17 de marzo, traspasaba las posibilidades legales de la Generalitat que no está habilitada para convocar y regular un referéndum, constitucionalmente reservado a la competencia del Estado. El propio título de esa Ley era ilustrativo del exceso, incrementado cuando el artículo 1, luego declarado inconstitucional, señalaba que «el objeto de la presente Ley es el régimen jurídico, el procedimiento, el cumplimiento y la convocatoria por la Generalidad o por los ayuntamientos, en el ámbito de sus competencias respectivas, de las consultas populares por vía de referéndum, de acuerdo con lo establecido por el artículo 122 del Estatuto de Autonomía». Resulta ocioso recordar que esa última expresión no se corresponde con la letra del propio Estatuto y menos aún con la jurisprudencia constitucional.

Esa circunstancia evidenció la necesidad de elaborar otra norma adaptada a dicha jurisprudencia. Así, en la IX legislatura del Parlament de Catalunya comenzó la tramitación de un texto que no llegó a aprobarse al disolverse anticipadamente la Cámara en $2012^{8}$ pero que a efectos del análisis de la Ley de Consultas populares de 2014, resulta interesante porque da idea de la evolución entre lo querido al principio y lo aprobado finalmente. El Govern presentó ante el Parlament un Proyecto de ley el 29 de diciembre de 2011. Admitido a trámite el 10 de enero de 2012, tuvo lugar el debate de totalidad el 14 de marzo del mismo año y una vez superado comenzó su labor la Comisión de Asuntos Institucionales con la fase de comparecientes los días 16 y 30 de mayo y 20 de junio. Los trámites siguientes fueron presentación de enmiendas al texto y nombramiento de la ponencia que debía presentar el informe sobre el texto y las enmiendas presentadas por los grupos parlamentarios.

Por Decreto 104/2012, de 1 de octubre, de convocatoria de elecciones al Parlament de Catalunya y de su disolución, el President de la Generalitat disolvía anticipadamente el Parlament concluyendo la IX legislatura implicando el decaimiento de todas las iniciativas parlamentarias, incluido el Proyecto de ley que se comenta. No obstante, ese texto presentaba aspectos de interés. Primeramente lo relativo al órgano autorizante de la consulta. Establecía el artículo 7.1 que «la convocatoria de consulta popular mediante votación en el ámbito competencial de

7 Aguado Renedo, César, «Referéndum autonómico y jurisprudencia constitucional», en Teoría y Realidad Constitucional, núm. 28, 2011, pág. 547.

8 Sobre este texto, vid. Auladell i Fontseca, Joan, «El Projecte de llei de consultes populars no referendàries impulsat pel Govern», en Activitat parlamentària, núm. 24, 2012, pp. 90-97; BoTELLA, Cristina y SERrA, Roser, «El Projecte de llei de consultes populars no referendàries: contigut i perspectives», en Activitat parlamentària, núm. 25, vol. 1, 2012, pp. 41-52. 
la Generalitat de Cataluña corresponde al Presidente de la Generalitat», y el párrafo 2 señalaba que «en el ámbito de las competencias locales, la convocatoria corresponde al presidente de la entidad local». Siendo una consulta en el ámbito territorial propio y sobre competencias también propias no parecía necesaria la previa autorización del Estado por lo que el texto del Proyecto en este orden no merecía ningún reparo.

El segundo punto atañe al objeto de la consulta. Para ser tal, igual que en el caso del referéndum strictu sensu, debía tratarse de una pregunta a los ciudadanos sobre cuestiones de la competencia exclusiva de la entidad que realizase la consulta. En este sentido, el artículo 1.1 del Proyecto señalaba que «el objeto de esta Ley es regular las consultas populares no referendarias, que permitan al Gobierno de la Generalitat escuchar las opiniones de la ciudadanía respecto de las actuaciones y competencias que afecten a la Generalitat de Cataluña así como a los entes locales de Cataluña en el ámbito de sus competencias propias». La ambigüedad de las expresiones podría permitir transformar una «consulta» en un «referéndum» sin respetar la regulación de éste. El objeto de la consulta debía referirse en todo caso a cuestiones relativas a las competencias exclusivas de los órganos convocantes sin que pudiera admitirse la diferenciación según éstos, de modo que si se trataba de entes locales sí debían ser preguntas sobre sus competencias propias pero si convocaba el President de la Generalitat la consulta podía versar sobre «las actuaciones y competencias que afecten a la Generalitat de Cataluña», referencia con alcance muy diferente a la del concepto, por esencia más reducido, de «competencias propias». En efecto, hay actuaciones y competencias que «afectan a la Generalitat de Cataluña» pero que no son competencia de la Generalitat de Cataluña porque corresponden a otros órganos aunque su ejercicio puede tener influencia en Cataluña.

Esa interpretación amplia del objeto de la consulta debía rechazarse porque era una vía encubierta para realizar un auténtico referéndum, aunque no se le denominara así, y en tal caso invadiría la competencia exclusiva del Estado (art. 149.1.32. ${ }^{a} \mathrm{CE}$ ) y vulneraría el artículo 29.6 EAC que señala que «los ciudadanos de Cataluña tienen derecho a promover la convocatoria de consultas populares por parte de la Generalitat y los ayuntamientos, en materia de las competencias respectivas, en la forma y las condiciones que las leyes establecen».

El citado artículo 1.1 podía considerarse contradictorio con el artículo 3.1 según el cual «el Presidente o presidenta de la Generalitat, previa deliberación del Gobierno, puede pedir la opinión de la ciudadanía sobre cuestiones relativas a materias de competencia de la Generalitat de Cataluña. En el caso de que la consulta afecte a competencias de otras instituciones que integren la Generalitat, el Gobierno puede pedir el parecer del órgano correspondiente antes de la convocatoria».

El contenido de la primera parte del artículo debía entenderse referido a las competencias del Govern y de la Presidencia de la Generalitat y en ese sentido era más adecuado y se ajustaba al artículo 122 EAC. Sin embargo, la referencia final era criticable porque esa alusión aludía a «las otras instituciones que integran la Generali- 
tat» (art. 2.1 EAC), es decir, el Parlamento y las instituciones que establece el capítulo V del Título II EAC, esto es, el Consejo de Garantías Estatutarias, el Síndic de Greuges, la Sindicatura de Cuentas y el Consejo Audiovisual de Cataluña. En esos supuestos, según el artículo 3.1 del Proyecto «en el caso de que la consulta afecte a competencias de las otras instituciones que integran la Generalitat, el Govern puede pedir el parecer del órgano correspondiente antes de la convocatoria». Debe señalarse que, estatutariamente, se reconoce la autonomía parlamentaria (art. 58) en su vertiente organizativa, financiera, administrativa y disciplinaria (art. 58.1), que el Consejo de Garantías Estatutarias «tiene autonomía orgánica, funcional y presupuestaria de acuerdo con la ley» (art. 77.4), que «el Sindic de Greuges goza de autonomía reglamentaria, organizativa, funcional y presupuestaria de acuerdo con las leyes» (art. 79.3), que la Sindicatura de Cuentas ejerce sus funciones «con plena autonomía organizativa, funcional y presupuestaria, de acuerdo con las leyes» (art. 80.2) y, por último, que el Consejo Audiovisual de Cataluña «actúa con plena independencia del Gobierno de la Generalitat en el ejercicio de sus funciones» (art. 82). Los citados artículos EAC justificaban una duda razonable sobre la conveniencia de que el President de la Generalitat tuviera competencia para convocar una consulta popular sobre temas referidos a competencias de estas instituciones, salvo que la iniciativa, aunque se manifestara de modo informal, partiera de ellas. En todo caso, si la idea nacía del President de la Generalitat no tenía sentido que la solicitud del parecer del órgano implicado fuera potestativa y no preceptiva porque parece que es inmiscuirse en su labor cuestionando la autonomía o independencia que tienen estatutariamente reconocida. Además, no se apreciaba realmente la razón de esa consulta ni su objeto concreto.

De lo anterior puede deducirse que lo verdaderamente significativo del Proyecto era la proyección que se pretendiera dar a la Ley, la aplicación práctica que se hiciera de su articulado. Teniendo en cuenta lo limitado de las materias objeto de este tipo de consultas y el carácter no vinculante de sus resultados, se colige la escasa virtualidad de las mismas. Para conocer la opinión de los ciudadanos sobre un asunto hay mecanismos de carácter sociológico, más baratos económicamente y menos comprometidos jurídica y políticamente (sondeos, encuestas, etc.), que suplen perfectamente a una iniciativa de esta índole. Distinto es que se quisiera utilizar esta vía para encubrir la realización de un auténtico referéndum sobre materias que no sean de la competencia exclusiva del ente que las convoca. En ese caso se estaría burlando el espíritu y la letra de la Constitución. Incluso en el supuesto de tratarse de referéndum y no de una consulta popular, el objeto de la pregunta o preguntas debería versar sobre el ámbito competencial propio del ente que impulsara la convocatoria, porque no cabe preguntar a los ciudadanos sobre materias que no son de la competencia propia. Por ello resulta clarificador el Dictamen 15/2010, de 6 de juliol, del Consell de Garanties Estatutàries de Catalunya, respecte a la Proposta de consulta popular per via de referéndum sobre la independencia de la nació catalana, cuyo FJ $3 .^{\circ}$ indica que «en el ámbito de las consultas populares por vía de referéndum de iniciativa popular, unos 
determinados promotores de una iniciativa no pueden forzar al Parlament a hacer uso de sus prerrogativas y, por tanto, la actividad de los promotores se ha de ceñir al ámbito estricto de las competencias de la Generalitat, que, con carácter general, se establecen en el citado título IV del Estatut (especialmente, del art. 116 al 173, ambos incluidos)».

Del Proyecto debe subrayarse también el tema del sistema de garantías. Así, no quedaba demasiado asegurada la independencia de los organismos encargados de velar por la pureza del proceso. El artículo 10.1 establecía que el sistema de garantías sería aprobado por el órgano convocante juntamente con la pregunta o preguntas sometidas a consulta. No era defendible que cada convocatoria tuviera su propio sistema de garantías, en los términos establecidos meramente de forma reglamentaria, aunque el Proyecto fijara algunos elementos preceptivos del sistema, como la llamada Comisión de Seguimiento designada por el órgano convocante (art. 10.2), integrada por representantes del órgano convocante y de las asociaciones sociales o profesionales interesadas del ámbito territorial correspondiente, y que hubieran manifestado su voluntad de formar parte del proceso, así como de personas independientes y de reconocido prestigio en sus ámbitos de actuación (art. 10.2). El artículo 10.3 especificaba los requisitos para que esas asociaciones pudieran integrar la comisión. Al final, el órgano convocante designaba las personas o entidades que formaban la Comisión de Seguimiento (art. 10.3). De lo apuntado se desprende que la influencia del órgano convocante en la designación de la Comisión era notoria y por ello la independencia que debe predicarse de cualquier órgano de control en estas consultas quedaba muy cuestionada y podía producir sospechas de parcialidad de la Comisión porque realmente era el órgano a controlar el que tenía en su mano la composición del órgano controlador, amén de cuestiones concretas como la invocación a conceptos jurídicos indeterminados, en este caso el reconocido prestigio. Al margen de los casos claros que nadie pueda razonablemente refutar, siempre puede quedar duda sobre la imparcialidad del órgano convocante a la hora de designar a unas u otras personas.

El artículo 10.5 establecía que «el órgano convocante puede designar personas de apoyo a las mesas de votación, de las que no formen parte, en los términos y con las funciones que determine el decreto de convocatoria». No estaba claro el alcance del concepto «apoyo», impresión reforzada con la segunda parte del artículo que remitía a cada decreto de convocatoria para saber los términos en que se debían concretar las funciones de estas personas. No parece razonable aprobar un artículo tan genérico que difiera luego a la simple voluntad del órgano convocante las funciones, absolutamente indeterminadas en el Proyecto, de estas personas. El apoyo técnico-jurídico parece que según el Proyecto lo prestaba la Comisión de Control (art. 12. b) por lo que no se entendía la necesidad de esas personas ante lo indeterminado de su labor. También la llamada Comisión de Control debía criticarse por el origen exclusivamente político de sus integrantes. En efecto, integrada por seis juristas de reconocido prestigio, el Govern designaba al presidente y a dos personas 
más, y el Pleno del Parlament a las otras tres personas. Cabía la posibilidad, dependiendo de la composición de la Cámara, de que la del órgano fuera escasamente plural y muy vinculada a los intereses del Govern con lo que su credibilidad quedaba en entredicho.

Cuestión también importante era la posibilidad de convocatoria de la consulta surgida inicialmente de una iniciativa popular mediante un número determinado de firmas según que la consulta fuera en toda Cataluña o de ámbito local (art. 22). No se establecía en el Proyecto el ámbito material excluido de estas iniciativas populares, con lo cual, en aplicación de la disposición adicional segunda (para todas las cuestiones no reguladas por esta ley era supletoria la Ley 1/2006, de 16 de febrero, de la iniciativa legislativa popular) debería considerarse aplicable la Ley 1/2006, de 16 de febrero, de la iniciativa legislativa popular, en el sentido de que no cabía iniciativa popular para la convocatoria de una consulta sobre las materias excluidas de la iniciativa legislativa popular, es decir, materias sobre las cuales la Generalitat no tuviera competencia ni el Parlamento pudiera legislar, de acuerdo con la Constitución y el Estatuto de Autonomía, así como las materias que el Estatuto reserva a la iniciativa exclusiva de los diputados, de los grupos parlamentarios o el Gobierno, los presupuestos de la Generalitat y las materias tributarias (art. 1 Ley 1/2006, de 16 de febrero). Realmente, la posibilidad de que una consulta se convocase por una iniciativa popular era remota por la exclusión de un ámbito material considerable y sobre materias sensibles.

La conclusión básica de cuanto antecede es que el punto principal del Proyecto de Ley era el relativo al objeto de la convocatoria de la consulta popular y aquí hay que insistir en que las consultas deben versar sobre temas de la competencia del ente que las convoque, sin que consistan en referendos disfrazados sobre asuntos que excedan de la competencia de la Generalitat o de los municipios, especialmente en temas de financiación o de anclaje de Cataluña en el Estado.

Debe señalarse que estas iniciativas catalanas respondían, en última instancia, a la línea iniciada en otras Comunidades Autónomas con leyes sobre Fomento a la Participación Ciudadana (Canarias o Comunidad Valenciana) o reguladoras de las consultas populares locales (Andalucía o Navarra). Obviamente, al final, los textos catalanes excedían de estas intenciones iniciales.

\section{CONTENIDO}

Respecto al contenido de la Ley ya que la STC 31/2015, de 25 de febrero, lo ha dejado limitado a las consultas sectoriales, es oportuno más bien centrarse en las razones de dicho pronunciamiento del Tribunal Constitucional a la luz de la Constitución española, de la Ley Orgánica 2/1980, de 18 de enero, sobre regulación de las distintas modalidades de referéndum (LOMR), del Estatuto de Autonomía de Cataluña y de su propia jurisprudencia. 
En primer lugar, en relación a la Constitución, debe señalarse que la participación política directa de los ciudadanos ${ }^{9}$ la canaliza a través de la figura del referéndum y siempre vinculada a la competencia exclusiva del Estado en cuanto a su convocatoria. Así, el artículo 149.1.32. ${ }^{a}$ señala que el Estado tiene competencia exclusiva sobre «autorización para la convocatoria de consultas populares por vía de referéndum», idea reiterada en el artículo 2.1 LOMR al señalar que «la autorización para la convocatoria de consultas populares por vía de referéndum, en cualquiera de sus modalidades, es competencia exclusiva del Estado».

Hay que apuntar que la Constitución y la LOMR no ofrecen un concepto de referéndum ni de figuras similares, de forma que debe acudirse a la jurisprudencia del Tribunal Constitucional para saber qué es referéndum o cuando estamos ante un auténtico referéndum. Así, la STC 63/1987, de 20 de mayo, señala que «la participación directa que en los asuntos públicos ha de corresponder a los ciudadanos es la que se alcanza a través de las consultas populares previstas en la propia Constitución (artículos 92, 149.1.32." 151.1 , 152.2, 167.3 y 168.3)» (FJ 5), referencia completada por la STC 119/1995, de 17 de julio, que después de recordar aquella cita añade que «todos los preceptos enumerados se refieren a distintas modalidades de referéndum y, en última instancia, a lo que tradicionalmente se vienen considerando como formas de democracia directa, es decir, a aquellos supuestos en los que la toma de decisiones politicas se realiza mediante un llamamiento directo al titular de la soberanía» (FJ 3). En este sentido, la STC 103/2008, de 11 de septiembre, señala que «el referéndum es una especie del género "consulta popular" con la que no se recaba la opinión de cualquier colectivo sobre cualquiera asuntos de interés a través de cualquiera procedimientos, sino aquella consulta cuyo objeto se refiere estrictamente al parecer del cuerpo electoral (expresivo de la voluntad del pueblo (STC 12/2008, de 29 de enero, FJ

9 La bibliografía al respecto es muy amplia. Como ejemplos, Arruego Rodríguez, Gonzalo, Representación politica y derecho fundamental: la participación política representativa en la Constitución española de 1978, Centro de Estudios Políticos y Constitucionales, Madrid, 2005; Ibáñez Macías, Antonio, El derecho constitucional a participar y la participación ciudadana local, Editorial Difusión Jurídica y Temas de Actualidad, Madrid, 2007; Esparza MarTínez, Bernardino, La participación política como derecho fundamental en la Constitución de España y de Europa, Porrúa, México, 2008; Revenga Sánchez, Miguel y VIANA GarcÉs, Andrée (eds.), Tendencias jurisprudenciales de la Corte Iberoamericana y el Tribunal Europeo de Derechos Humanos: derecho a la vida, libertad personal, libertad de expresión, participación política, Tirant lo Blanch, Valencia, 2008; Pérez Alberdi, María Reyes, El derecho fundamental a la participación en los asuntos públicos, Publicaciones del Congreso de los Diputados, Madrid, 2013; Costanzo, Pasquales y Pajares Montolío, Emilio (coords.), Nuevas Dimensiones de la Participación Política. III Jornadas Internacionales de Derecho Constitucional: Brasil, Italia, España, Tirant lo Blanch, Valencia, 2015; Cascajo Castro, José Luis y Martín de la Vega, Agustín (coords.), Participación, representación y democracia: XII Congreso de la Asociación de Constitucionalistas de España, Tirant lo Blanch, Valencia, 2016; Busschaert, Gautier, Participatory democracy, civil society and social Europe: a legal and political perspective, Intersentia, Cambridge, 2016; MARTín NúÑEZ, Esther, «La garantía jurídica de la democracia como derecho fundamental: un análisis de la jurisprudencia del Tribunal Constitucional sobre la participación política», en Revista Catalana de Dret Public, n. ${ }^{\circ} 38,2003$, pp. 315-342; Castellà Andreu, Josep Maria, «Democracia participativa en las instituciones representativas: apertura del Parlamento a la sociedad», en Revista "Cuadernos Manuel Giménez Abad», n. ${ }^{\circ}$ 5, 2013, pp. 202-213. 
10) conformado y exteriorizado a través de un procedimiento electoral, esto es, basado en el censo, gestionado por la Administración electoral y asegurado con garantías jurisdiccionales específicas, siempre en relación con los asuntos públicos cuya gestión, directa o indirecta, mediante el ejercicio del poder politico por parte de los ciudadanos constituye el objeto del derecho fundamental reconocido por la Constitución en el art. 23 (así, STC 119/1995, de 17 de julio). Para calificar una consulta como referéndum o, más precisamente, para determinar si una consulta popular se verifica "por vía de referéndum" (art. 149.1.32. " CE) y su convocatoria requiere entonces de una autorización reservada al Estado, ha de atenerse a la identidad del sujeto consultado, de manera que siempre que éste sea el cuerpo electoral, cuya vía de manifestación propia es la de los distintos procedimientos electorales, con sus correspondientes garantías, estaremos ante una consulta referendaria» (FJ 2). Esa doctrina del Tribunal Constitucional la sintetiza Bueno Armijo diciendo que «la clave de la distinción entre el referéndum y el resto de consultas populares descansa sobre un criterio orgánico procedimental» ${ }^{10}$ y utilizando expresiones propias de las ciencias naturales el autor centra la cuestión señalando que «el punto de partida se encuentra en la existencia de una relación entre ambos conceptos del tipo género-especie. De este modo, las consultas populares serían el género, dentro del cual se encontraría, entre otras especies, el referéndum consultivo» ${ }^{11}$.

De esos pronunciamientos del Tribunal Constitucional se deduce que el concepto referéndum tiene un contenido muy claro y que cualquier forma de solicitar a los ciudadanos su parecer sobre un asunto que cumpla con los requisitos enunciados en la citada STC 103/2008, de 11 de septiembre, será considerada como referéndum. La vinculación referéndum-ciudadanía es destacada en la STC 31/2015, de 25 de febrero, señalando que el primer rasgo definidor de un referéndum es que «se produce un llamamiento del poder político a la ciudadanía para ejercer el derecho fundamental de participación en los asuntos públicos reconocido en el artículo 23.1 CE. El destinatario de la consulta es el conjunto de ciudadanos que tienen reconocido el derecho de sufragio activo en un determinado ámbito territorial o, lo que es lo mismo, el cuerpo electoral» [FJ 5.a)]. Por el contrario, «las consultas no referendarias recaban, en cambio, la opinión de cualquier colectivo (STC 31/2010, de 28 de junio. FJ 69), por lo que articulan "voluntades particulares o colectivas, pero no generales, esto es, no imputables al cuerpo electoral" (STC 103/2008, de 11 de septiembre, FJ 2). Frente a las formas de participación politicas, en las que se interviene en cuanto ciudadano (uti cives), en las consultas populares no referendarias se participa a título individual (uti singulus) o como miembro de un colectivo, sea social, económico, cultural o de otra indole (uti socius)» [FJ 5.a)]. De lo anterior puede extraerse que el referéndum es en sí mismo una consulta pero, a sensu contrario, no toda consulta constituye técnicamente un referéndum.

10 Bueno Armijo, Antonio, “"Consultas populares” y "referéndum consultivo”: una propuesta de delimitación conceptual y de distribución competencial», en Revista de Administración Pública, núm. 177, septiembre-diciembre 2008, pág. 209.

11 Ibidem, pág. 204. 
El problema es determinar si la Ley de 2014 regula realmente consultas populares no referendarias o auténticos referéndums encubiertos, uno de los ejes del voto particular del consejero Carlos Jaume Fernández al Dictamen 19/2014, de 19 de agosto, del Consell de Garanties Estatutàries, señalando que «con independencia del nombre y el régimen jurídico que se dé a esta tipología de consulta, en ningún caso puede incorporar los elementos que configuran el referéndum, o similares, o que puedan llevar a una identificación tal que se confundan las dos instituciones, ya que los elementos mencionados caracterizan la institución referendaria y operan como límite infranqueable respecto de otras vías de consulta».

Los requisitos técnicos a los que se refiere el Tribunal Constitucional (censo electoral, Administración electoral, garantías jurisdiccionales específicas) sirven inicialmente para identificar un referéndum, o una mera consulta sin ese carácter, pero los criterios verdaderamente determinantes para diferenciar un referéndum o una consulta son dos: el órgano autorizante de la consulta y el objeto de la pregunta que se formule.

Teniendo en cuenta las anteriores premisas, la correcta valoración jurídica de esta Ley requiere su interpretación a la vista del ordenamiento jurídico, español y catalán, al no bastar el análisis literal de la misma pues utiliza expresiones deliberadamente ambiguas y términos pretendidamente novedosos para enmascarar conceptos clásicos que hacen que dicha Ley vaya más allá de una mera regulación para facilitar la realización de inocuas consultas convencionales.

En este orden, lo primero es recordar que la Constitución española canaliza, como se apuntó, la forma de participación política directa de los españoles a través del referéndum recogido en sus artículos 92, 151, 152.2, 167, 168 y disp. trans. Cuarta. 1 y por ello el Tribunal Constitucional señala que «a su vez la Ley Orgánica 2/1980, de 18 de enero, sobre regulación de las distintas modalidades de referéndum, es la llamada por el art. 92.3 CE para regular las condiciones y el procedimiento de las distintas modalidades de referéndum previstas en la Constitución, siendo además la única Ley constitucionalmente adecuada para el cumplimiento de otra reserva, añadida a la competencial del art. 149.1.32 CE: la genérica del art. $81 \mathrm{CE}$, en este caso el derecho de participación política reconocido en el art. 23 CE» (STC 103/2008 de 11 de septiembre. FJ 3) ${ }^{12}$. Es decir, en este tema se produce una doble reserva de ley orgánica. Por una parte, la que exige el artículo 92.3 para la figura del referéndum y, de otra, el necesario desarrollo por ley orgánica de los derechos fundamentales, en este caso el de participación política directa del artículo 23.1 CE. Por ello es cuestionable la idea de Castellà Andreu de que la LO 2/1980 no tiene «por qué impedir la legislación autonómica sobre el referéndum, siempre que

12 En contra de la postura del Tribunal Constitucional, para Aguado Renedo «podría no ser la única que cumple con la reserva constitucional en materia de referéndum, desde el momento en que la literalidad del art. 92.3 CE cuando se remite a ella hace referencia a "las modalidades de referéndum previstas en esta Constitución”: nada impediría teóricamente, de acuerdo con esta literalidad, que pudiesen existir dos leyes orgánicas distintas reguladoras de referéndums, una para los previstos en la Constitución y otra para los demás», Aguado Renedo, César, op. cit. pág. 548. 
haya base competencial» ${ }^{13}$. Precisamente el planteamiento del Tribunal Constitucional es que no hay esa base competencial ni en la Constitución ni en el artículo 122 EAC y en consecuencia el referéndum no es una figura que pueda desarrollar la Generalitat catalana.

De la doctrina del Tribunal Constitucional se desprende que la referencia constitucional de que «los ciudadanos tienen el derecho a participar en los asuntos públicos, directamente » (art. 23.1 ab initio) tiene su desarrollo en el artículo 92 de la propia Constitución y, en su aplicación, en la Ley Orgánica 2/1980, de 18 de enero, sobre regulación de las distintas modalidades de referéndum. A su vez, conviene recordar que esa Ley Orgánica afirma en su artículo 11.1 que «el procedimiento de referéndum estará sometido al régimen electoral general en lo que sea de aplicación y no se oponga a la presente Ley». Hay, pues, una íntima relación entre la normativa específica reguladora de los referéndums y la normativa electoral general recogida en la Ley Orgánica 5/1985, de 19 de junio, de Régimen electoral general, que no puede obviarse por el hecho de emplearse expresiones distintas a la de referéndum pero que suponen idéntico propósito material. Ello significa que determinados aspectos de la celebración de las consultas populares requieren observar necesariamente la regulación electoral general, sin que una normativa autonómica sobre el particular signifique un espacio exento de vinculación y dependencia con las normas jurídicas estatales.

Postura distinta, escasamente respetuosa con la doctrina del Tribunal Constitucional, mantiene el Consell de Garanties Estatutàries que en el Dictamen 19/2014, de 19 de agosto, sostiene en su FJ segundo. 2 que «debe distinguirse y no confundirse el artículo 29 EAC con el derecho fundamental de participación política del artículo $23 \mathrm{CE}$ ». Es decir, el derecho de participación de los catalanes «en los asuntos públicos de Cataluña, de forma directa o bien a través de representantes, en los supuestos y en los términos que establecen el presente Estatuto y las leyes» (art. 29 EAC) no se corresponde con el contenido del artículo 23.1 CE según el cual «los ciudadanos tienen el derecho a participar en los asuntos públicos, directamente o por medio de representantes, libremente elegidos en elecciones periódicas por sufragio universal». El Consell esgrime en defensa de su tesis la STC 119/1995, de 17 de julio. FJ 2, cuando sostiene que en el artículo 23.1 CE se recogen dos derechos: el derecho electoral activo y el derecho electoral pasivo, modalidades o vertientes del mismo principio de representación política. De esa STC deduce el Consell que «la participación política de los ciudadanos, configurada como derecho fundamental y sometida a la correspondiente reserva de ley orgánica respecto de los elementos esenciales de su régimen jurídico (art. 81.1 CE), únicamente prevé dos modalidades, una principal o prevalente en el conjunto del sistema, que es la democracia representativa, ejercida

${ }^{13}$ Castellà Andreu, Josep M., «La competencia en materia de consultas populares por la vía de referéndum en la sentencia 31/2010 sobre el Estatuto de Autonomía de Cataluña», en Revista Catalana de Dret Public. Especial Sentència 31/2010 del Tribunal Constitucional sobre I'Estatut d'Autonomía de Catalunya de 2006., 2010, pág. 313. En el mismo sentido, Martín Núñez, Esther, "Comentario a la sentencia sobre el Estatuto. Competencia en materia de consultas populares (art. 122)», ibidem, pág. 320. 
mediante la actuación de los representantes electos en el seno de las instituciones, y la otra, la democracia directa o semidirecta, que se articula en determinados supuestos mediante la figura del referéndum».

La posición del Consell merece criticarse. Por una parte, no puede crear un espacio jurídico exento de vinculación con el texto constitucional ni colocar éste en situación de paridad con el Estatut. Éste debe interpretarse de acuerdo a la Constitución y la participación política directa tiene un contenido que el Tribunal Constitucional ha expresado nítidamente y su doctrina es aplicable en cualquier lugar del territorio español. De otro lado, no ha tenido en cuenta todo el contenido de la referida STC 119/1995, de 17 de julio, que en el mismo FJ2 recuerda el FJ2 de la STC 51/1984, de 25 de abril, que señala que «la participación en los asuntos públicos a que se refiere el art. 23 es en primera línea la que se realiza al elegir los miembros de las Cortes Generales, que son los representantes del pueblo, según el art. 66 de la Constitución» pero añade a continuación que ese derecho recogido en el artículo $23 \mathrm{CE}$ «puede entenderse asimismo que abarca también la participación en el gobierno de las Entidades en que el Estado se organiza territorialmente, de acuerdo con el art. 137 de la Constitución», esto es, municipios, provincias y las Comunidades Autónomas que se constituyan.

Obviamente la referencia al gobierno de las Entidades no alude a la función ejecutiva que en el caso autonómico está constitucionalmente atribuida a un Consejo de Gobierno (art. 152.1 CE), sino a la intervención ciudadana en la elección de los miembros de esas entidades locales, provinciales y también autonómicas (STC 103/2008, de 11 de septiembre. FJ 11) y que sería ejercicio del derecho recogido en el artículo 23.1 CE. Incidiendo en el argumento, la misma STC 119/1995, de 17 de julio, en su FJ 3 recuerda la STC 63/1987, de 20 de mayo. FJ5 y el ATC 399/1990, de 12 de noviembre. FJ 2 cuando sostienen que «la participación directa que en los asuntos públicos ba de corresponder a los ciudadanos es la que se alcanza a través de las consultas populares previstas en la propia Constitución (arts. 92, 149.1.32, 151.1, 152.2, 167.3 y 168.3)». Se evidencia así la conexión entre el citado derecho que aparece en el artículo 23.1 CE y la participación política directa de los ciudadanos mediante su respuesta a la llamada a las urnas para opinar sobre un asunto de índole política en el nivel territorial que corresponda. La consecuencia es que no hay expresión popular fuera de los mecanismos establecidos constitucionalmente, en especial el referéndum, y que cualquier convocatoria de este tipo cuando puede rozar la legalidad requiere la presencia del Estado. Esa es la razón de que la autorización para la convocatoria de consultas populares por vía de referéndum corresponda al Estado (art. 149.1.32. ${ }^{a} \mathrm{CE}$ ).

La adecuada interpretación del artículo 23.1 CE es esencial en el correcto entendimiento de esta Ley como se demuestra en el énfasis que han puesto sobre este tema determinados documentos. Así, el Consejo de Estado en su Dictamen 964/2014, de 28 de septiembre, relativo al expediente sobre la interposición del recurso de inconstitucionalidad por parte del Presidente del Gobierno contra la Ley de Consultas, señala en la Consideración III. 1. a) y b), en orden a la jurisprudencia constitucional sobre el particular, que hay que diferenciar entre el derecho fundamental de partici- 
pación política del artículo 23.1 CE y otras formas de participación que aparecen en diversos artículos del texto constitucional como, por ejemplo, el 125 referente a la participación de los ciudadanos en la Administración de Justicia a través de la institución del Jurado. Señala el Consejo de Estado que el Tribunal Constitucional es muy claro al respecto. Las distintas formas de participación «no sólo se hallan contempladas en preceptos diferentes de la Constitución, sino que tales preceptos obedecen a manifestaciones de una ratio bien distinta: en el artículo 23.1 de la Constitución se trata de las modalidades - representativa y directa - de lo que en el mundo occidental se conoce como democracia politica, forma de participación inorgánica que expresa la voluntad general, mientras que en los restantes preceptos a que se ha becho alusión se da entrada a correctivos particularistas de distinto orden» (STC 115/1995, de 19 de julio. FJ 4).

En esa misma línea se manifiestan algunos votos particulares al Dictamen 19/2014, de 19 de agosto, del Consell de Garanties Estatutàries. Así, Pere Jover Presa diferencia el concepto de referéndum, «instrumento de participación política, apto para el ejercicio del derecho fundamental reconocido en el artículo 23.1 CE, que se ejerce mediante el sufragio libre, igual, directo y secreto», de la idea de las consultas no referendarias que «no guardan relación con el mencionado derecho fundamental de participación política, sino que son expresión del principio genérico de participación (que no es "participación política" en el sentido anteriormente indicado, y que no es derecho fundamental), y que ha sido calificado mediante expresiones como "democracia participativa" o "democracia deliberativa" ${ }^{14}$. Igualmente, para Eliseo Aja «mientras que el referéndum consultivo expresa la voluntad política de los ciudadanos mediante el ejercicio de un derecho fundamental (el sufragio del art. $23 \mathrm{CE}$ ), las formas de participación ordinaria tienen una configuración y unas garantías derivadas de las leyes» ${ }^{15}$, y Marc Carrillo, a la vista de la jurisprudencia constitucional, también señala claramente los auténticos instrumentos que cabe incluir en el derecho fundamental de participación política del artículo 23.1 CE, es decir, las elecciones y el referéndum ${ }^{16}$. Del mismo modo, la distinción entre el derecho fundamental de participación política recogido en el artículo 23.1 CE y las formas de simple participación ciudadana se detallan en el FJ 4 de la STC 31/2015, de 25 de febrero.

La utilización del argumento de la participación de los ciudadanos para justificar la aprobación de una Ley como la que se comenta puede ser engañosa. El Consell en su Dictamen 19/2014, de 19 de agosto, ya alegaba que «la articulación de determinados procedimientos dirigidos a la obtención de la opinión o de las aspiraciones ciudadanas de una comunidad, salvando las consecuencias políticas y jurídicas que en cada caso se deriven, si se desarrollan de manera respetuosa y a la vez complementaria con los correspondientes principios y procedimientos constitucionales, incluidos los mecanismos rígidos de reforma, no chocan ni resultan incompatibles con el funda-

\footnotetext{
14 Voto particular al Dictamen (I, 1), pp. 93 y 95, respectivamente.

15 Voto particular al Dictamen (El carácter constitucional del referéndum consultivo y su diferencia con las formas ordinarias de participación ciudadana.3), pp. 114-115.

16 Voto particular al Dictamen (3), pp. 131-132.
} 
mento último de la soberanía reconocida en el artículo 1.2 CE. Todo lo contrario, pueden contribuir a reforzar destacados valores constitucionales, más allá del necesario cumplimiento de la ley» (FD segundo.3) esgrimiendo a su favor la Opinión emitida por el Tribunal Supremo de Canadá el 20 de agosto de 1998, respondiendo a las tres preguntas planteadas por el Gobierno de Canadá sobre una secesión unilateral de Quebec ${ }^{17}$, en concreto sus parágrafos 66 ( « la democracia expresa la voluntad soberana del pueblo») y 67 ( " para ser legítimas, las instituciones democráticas deben permitir la participación del pueblo»), algo que repite la Generalitat en su escrito de personación ante el Tribunal Constitucional en el recurso de inconstitucional contra la Ley.

El respeto a la voluntad popular es esencial en una democracia pero las reglas de la propia democracia exigen que esa voluntad se manifieste de acuerdo con la ley y no fruto de una iniciativa unilateral que vulnere las normas generales. Así, debe recordarse el Código de Buena Conducta en materia referendaria, adoptado por el Consejo de elecciones democráticas y por la Comisión europea para la democracia por el derecho (Comisión de Venecia), cuyo punto 4 dice que el referéndum debe convocarse conforme a principios y normas democráticas. Asimismo, Las líneas directrices sobre la regulación de los referéndums, adoptadas por el Consejo de las elecciones democráticas en su 18. ${ }^{a}$ reunión (Venecia, 12 de octubre de 2006) y la Comisión de Venecia en su 68. ${ }^{a}$ reunión (13-14 de octubre de 2006) dicen en el punto III. Reglas específicas, apartado 1 . La preeminencia del derecho, que «el recurso al referéndum debe respetar el conjunto del ordenamiento jurídico, y especialmente las reglas de procedimiento. En particular, el referéndum no puede ser organizado si la Constitución o una ley conforme a la Constitución no lo prevé, por ejemplo si el texto sometido a votación es de la competencia exclusiva del Parlamento». Siguiendo con el caso canadiense, el propio Tribunal Supremo de Canadá es muy claro sosteniendo que «el argumento según el cual se puede legítimamente soslayar la Constitución apoyándose en un voto mayoritario obtenido en un referéndum provincial es superficialmente convincente, en una amplia medida porque parece recurrir a algunos de los principios que sustentan la legitimidad de la propia Constitución, es decir, la democracia y la autonomía gubernamental No obstante, un análisis más completo revela que este argumento está mal fundado porque ignora el sentido de la soberanía popular y la esencia misma de una democracia constitucional» (parágrafo 75), o cuando afirma

17 1. La Asamblea nacional, el poder legislativo, o el gobierno de Quebec, ¿pueden, en virtud de la Constitución de Canadá, proceder unilateralmente a la secesión de Quebec de Canadá?. 2. La Asamblea nacional, el poder legislativo, o el gobierno de Quebec, ¿poseen, en virtud del Derecho internacional, el derecho de proceder unilateralmente a la secesión de Quebec de Canadá?. A este respecto, en virtud del Derecho internacional, ¿existe un derecho a la autodeterminación que les proporcionaría a la Asamblea nacional, al poder legislativo o al gobierno de Quebec el derecho a proceder unilateralmente a la secesión de Quebec de Canadá?. 3. Entre el Derecho interno y el Derecho internacional, ¿cuál tendría preferencia en Canadá en caso de conflicto entre ellos en cuanto al derecho de la Asamblea nacional, de la legislatura o del gobierno de Quebec a proceder unilateralmente a la secesión de Quebec de Canadá?. 
que «en términos jurídicos, se debe considerar que la secesión de una parte de Canadá requiere una modificación de la Constitución, lo que exige forzosamente una negociación» (parágrafo 84) o, por último, al declarar de forma rotunda que «la secesión de Quebec de Canadá no se puede considerar un acto legal si la realizan unilateralmente la Asamblea nacional, el poder legislativo o el gobierno de Quebec, es decir sin negociaciones de acuerdo con los principios» (parágrafo 104). De lo anterior se colige que la opinión de los ciudadanos es esencial en una democracia pero la manifestación de esa opinión no puede ser anárquica ni indiscriminada. Bien al contrario, debe canalizarse a través de la ley en todos los aspectos. Cualquier intento de sustituir o esquivar la ley deviene en un acto no democrático y por tanto sin valor alguno.

Otro documento aplicable para algunos al caso catalán es la Opinión consultiva de la Corte Internacional de Justicia sobre la conformidad con el Derecho Internacional de la Declaración Unilateral de Independencia relativa a Kosovo, de 22 de julio de 2010. La Corte aclara primero que «es enteramente posible que un acto en particular, como una declaración unilateral de independencia, no infrinja el derecho internacional sin que necesariamente constituya el ejercicio de un derecho que éste le confiere. Se ha pedido a la Corte una opinión sobre el primer punto, no el segundo» (parágrafo. 56). La Corte, pues, no se pronuncia sobre si hay o no derecho a realizar una Declaración unilateral de independencia según el Derecho Internacional, sino sobre si el acto jurídico concreto de esa Declaración es o no conforme a ese Derecho y al respecto la Corte comienza manifestando que «en la segunda mitad del siglo xx, el derecho internacional en materia de libre determinación evolucionó hasta dar lugar a un derecho a la independencia de los pueblos de los territorios no autónomos y de los pueblos sometidos a la subyugación, dominación y explotación extranjeras» (parágrafo. 79), incluso reconoce la existencia de posibles declaraciones de independencia fuera de esos supuestos, y entonces «la práctica de los Estados en estos últimos casos no revela la aparición en el derecho internacional de una nueva norma que prohíba la adopción de una declaración de independencia en tales casos» (parágrafo. 79). La consecuencia a la que llega la Corte es que «el derecho internacional general no contiene ninguna prohibición de las declaraciones de independencia aplicable y llega por tanto a la conclusión de que la declaración de independencia de 17 de febrero de 2008 no vulneró el derecho internacional general» (parágrafo. 84). Es decir, la Corte no reconoce un derecho a realizar tales declaraciones en el Derecho Internacional pero constata que éste no las prohíbe o, dicho de otra forma, las consiente o tolera.

Las anteriores precisiones son especialmente importantes en el caso en presencia. En efecto, la Ley de consultas populares tiene su fundamento en el citado artículo 122 EAC, precepto en el que según el escrito de alegaciones del Parlament de Catalunya al recurso de inconstitucionalidad contra la Ley, «no hay nada que impida al legislador catalán, en base al artículo 122 EAC, regular la participación ciudadana mediante la creación y establecimiento del régimen jurídico de otros títulos participativos 
o consultas populares fuera del artículo $23.1 \mathrm{CE}$, al amparo del mandato general del artículo 9.2 CE de promover la participación de "todos los ciudadanos" en la vida política, económica y social» ${ }^{18}$. Dicho artículo 122 EAC fue interpretado por el Tribunal Constitucional en el sentido de que esa excepción que contiene «no puede limitarse a la autorización estatal para la convocatoria de consultas populares por vía de referéndum, sino que ha de extenderse a la entera disciplina de esa institución, esto es, a su establecimiento y regulación» (STC 31/2010, de 28 de junio.FJ 69). Es decir, la Generalitat no puede convocar un referéndum, pero además los límites a los que debe sujetarse su iniciativa para convocar una consulta popular se extienden también a los límites materiales que la citada STC 31/2010, de 28 de junio.FJ 69 señala por remisión a la STC 103/2008, de 11 de septiembre.FJ 4, esto es, «una cuestión que afecta al orden constituido y también al fundamento mismo del orden constitucional. Una afectación de esa naturaleza y con tal alcance es desde luego factible en nuestro ordenamiento, en el marco de los procedimientos de reforma de la Constitución el respeto a esos procedimientos es, siempre y en todo caso, inexcusable. Es más, tratar de sortear, eludir o simplemente prescindir de esos procedimientos sería intentar una inaceptable vía de hecho (incompatible con el Estado social y democrático de Derecho que se proclama en el art. 1.1 CE) para reformar la Constitución al margen de ella o conseguir su ineficacia jurídica» ${ }^{19}$.

18 Alegación III, 2, pág. 24.

19 Algunos autores admiten la constitucionalidad de las consultas de ámbito autonómico con la categoría de referéndum, v. gr. Aguiar DE LuQue, Luis, «Referéndum», en GonZÁlez EnCINAR, J. J. (dir.), Diccionario del sistema político español, Akal, Madrid, 1984, pág. 797; Bueno Armijo, Antonio, op. cit. pág. 224; PÉrez Sola, Nicolás, La regulación constitucional del referéndum, Universidad de Jaén, 1994, pág. 134. Del mismo autor, «La competencia exclusiva de las comunidades autónomas en materia de consultas populares», en Teoría y Realidad Constitucional, núm. 24, 2009, pág. 439. Por el contrario, para CARRASCo DURÁN, las consultas de ámbito autonómico no tienen el carácter de referéndum y derivarían no del artículo $92.3 \mathrm{ni}$ del artículo 149.1.32. ${ }^{\mathrm{a}}$, ambos de la CE, sino de las competencias en materia de consultas que se deducen de sus propios Estatutos de Autonomía, CARRASCo Durán, Manuel, op. cit. pág. 25, y que el autor considera que «si bien no pueden considerarse como exclusivas, se aproximan a este concepto», ibidem, pág. 32. En contra, para Bueno Armijo, «frente a lo que pueda parecer, el Estado ostenta auténticas competencias básicas sobre esta materia, lo que impide, a pesar de la categórica afirmación de los artículos estatutarios, que estas tres Comunidades Autónomas (Cataluña, Andalucía y Aragón) puedan asumir la competencia exclusiva sobre la misma», Bueno Armijo, Antonio, op. cit. pág. 217. Sobre consultas y referendos autonómicos, puede verse también, $v$. gr., López BASAGUREN, Alberto, «Sobre referéndum y comunidades autónomas: la ley vasca de consulta ante el Tribunal Constitucional (consideraciones con motivo de la STC 103/2008)», en Revista d'Estudis Autonòmics i Federals, n. ${ }^{\circ}$ 9, 2009, pp. 202-240; MarTín NúÑ̃EZ, Esther, «El referéndum y las consultas populares en las comunidades autónomas y municipios», en Revista Vasca de Administración Pública, n. ${ }^{\circ}$ 94, 2012, p. 95-131; IBÁÑEz Macías, Antonio, «Los referendos regional y local en el estado autonómico. Sus bases y límites constitucionales», en Revista Vasca de Administración Pública, n. ${ }^{\circ}$ 97, 2013, pp. 97-138; PÉrez Alberd, María Reyes, «La admisibilidad constitucional de un referéndum autonómico con base en la competencia estatutaria sobre consultas populares», en Revista Española de Derecho Constitucional, núm. 104, 2015, pp. 101-132; DE La Quadra-Salcedo Janini, Tomás, «Sobre los límites constitucionales a los referéndums territoriales», en El Cronista del Estado Social y Democrático de Derecho, n. ${ }^{\circ}$ 71-72, 2017, pp. 164-167. 
En cualquier caso, la lectura de la STC 31/2010, de 28 de junio. FJ 69, deja claro que cualquier intento de modificar la realidad en aspectos que inciden en cuestiones constitucionales requiere la utilización de los procedimientos de reforma constitucional fijados en el Título X CE sin que pueda emplearse otros instrumentos más modestos y jurídicamente menos complicados que pretendan alterar la situación actual de forma unilateral. En última instancia, el fundamento de lo anterior está en la aplicación del artículo 23.1 CE y su vinculación con el concepto de soberanía. En efecto, el Tribunal Constitucional sostiene que para que «la participación regulada en una Ley pueda considerarse como una concreta manifestación del artículo 23 CE es necesario que se trate de una participación politica, es decir, de una manifestación de la soberanía popular, que normalmente se ejerce a través de representantes y que, excepcionalmente, puede ser directamente ejercida por el pueblo, lo que permite concluir que tales derechos se circunscriben en el ámbito de la legitimación democrática directa del Estado y de las distintas entidades territoriales que lo integran, quedando fuera otros titulos participativos que derivan, bien de otros derechos fundamentales, bien de normas constitucionales de otra naturaleza, o bien, finalmente, de su reconocimiento legislativo» (STC 119/1995, de 17 de julio. FJ3).

Se llega así al concepto que aclara el alcance de la participación política directa, la soberanía. Y aquí las ideas están muy definidas. Hoy, constitucionalmente la soberanía se identifica con el pueblo español en su conjunto, sin que pueda hablarse de cuotas territoriales o personales de soberanía. Eso significa, por lo que aquí interesa, que la participación política directa «es una forma de participación inorgánica que expresa la voluntad general» (STC 119/1995, de 17 de julio. FJ4), lo que implica que cualquier llamamiento a la participación de los ciudadanos con un alcance general que pueda asimilarse con la intervención del cuerpo electoral de un determinado territorio se identifica con la figura del referéndum para que el pueblo soberano se manifieste directamente en un asunto de interés público. Esa idea la manejó el Presidente del Gobierno para recurrir parte de la Ley de consultas ante el Tribunal Constitucional considerando que «bajo la denominación de consultas populares no referendarias, el Parlamento de Cataluña ha regulado en realidad una materia sobre la que carece manifiestamente de competencia, esto es, las consultas referendarias» (FD primero. Introducción. I).

El eje del asunto está en la verdadera dimensión de la autonomía, en este caso, la catalana. El modelo de organización territorial constitucionalmente diseñado en 1978 no supone una mera descentralización administrativa, sino el derecho a una auténtica autonomía al más alto nivel a nacionalidades y regiones (art. 2 CE) incluyendo la potestad legislativa. Ahora bien, no debe olvidarse que «autonomía no es soberanía» (STC 4/1981, de 2 de febrero. FJ 3) porque la soberanía se vincula a la nación y constitucionalmente no hay otra nación que la española, a cuyo pueblo, en su conjunto, se le reconoce la condición de sujeto titular de la soberanía. Y será ese pueblo el único que pueda manifestarse directamente a través de la figura del referéndum cuya autorización será competencia del Estado (art. 149.1.32. ${ }^{\mathrm{a}} \mathrm{CE}$ ) porque la Constitución establece el principio de unidad de la nación en su artículo 2, previsión interpretada 
en clave negativa por quienes hablan de «blindaje de la unidad del Estado» ${ }^{20}$, de «una defensa fundamentalista de la Constitución» ${ }^{21}$, o de la Constitución que «se emplea como un cerrojo que convierte la integridad territorial en un principio esencialista e incuestionable ${ }^{22}$. Con independencia de la legitimidad de tales opiniones la Constitución es una norma jurídica con vocación de eficacia en el tiempo y ello implica que lo primero será garantizar el espacio físico del territorio del Estado sobre el que pueda aplicarse con lo cual es de suyo que la integridad territorial del Estado sea un principio básico que deba defenderse con un carácter prioritario. Por ello el Tribunal Constitucional, a la vista del caso catalán, es muy claro al afirmar que «de manera que lo que a todos afecta, la permanencia o no, en lo que abora importa, del Estado común en que España quedó constituida (art. $1.1 \mathrm{CE}$ ), no podría, llegado el caso, sino ser reconsiderado y decidido también por todos (art. 168 CE)» (STC 90/2017, de 5 de julio. FJ 6. ${ }^{\circ}$ ).

Eso implica que la Generalitat puede convocar consultas populares pero no puede hacerlo ni en la forma ni para el objeto que desee, es decir, deben ser consultas no referendarias y relacionadas con las competencias de la Generalitat, o de las entidades locales y, en todo caso según la STC 31/2015, de 25 de febrero, que esas consultas sean sectoriales. Ahondando en el argumento, para el Tribunal Constitucional «en suma, una Comunidad Autónoma no puede convocar, ni realizar actuaciones formalizadas o no jurídicamente que auspicien la convocatoria de una consulta popular, aun no referendaria, que desborde el ámbito de las competencias propias, o que incida sobre "cuestiones fundamentales resueltas en el proceso constituyente y que resultan sustraídas a la decisión de los poderes constituidos" " (STC 138/2015, de 11 de junio. FJ 3). No sirve defender otra postura, como hace la Generalitat en su escrito de personación y comparecencia ante el Tribunal Constitucional en el recurso de inconstitucionalidad promovido por el Presidente del Gobierno contra la Ley de consultas, diciendo que «35 años después de aprobada la Constitución, sus preceptos ya no pueden ser leídos e interpretados del mismo modo que en el momento original de su entrada en vigor. Si un objetivo preminente de la entonces naciente democracia en España pudo ser su propia consolidación y la del sistema de democracia representativa, confiriendo a las instituciones y los partidos políticos un casi exclusivo protagonismo en el escenario político, que llegó a relegar a supuestos de verdadera excepción las consultas populares y los referéndums, hoy aquél entendimiento del principio democrático requiere una contextualización en la que se dé a esos y a otros instrumentos de participación, una función efectiva de encauzar la expresión por los grupos sociales significativos de aquellas aspiraciones que no sienten representadas en las instituciones. Se trataría, en definitiva, de un ejercicio formalizado de las libertades ideológica y de expresión, que en modo alguno

20 PAStor, Jaime, Cataluña quiere decidir. ¿Se rompe España? Diez preguntas sobre el derecho a decidir, Icaria Editorial S.A., Barcelona, 2012, pág. 29.

${ }^{21}$ Ibidem, pág. 75.

22 Tалво, Carlos, En defensa de la consulta soberanista en Cataluña, Los Libros de la Catarata, Madrid, 2014, pág. 44 . 
resultan ajenas al elenco de valores, principios y derechos fundamentales en los que se funda la Constitución Española» (2, pág. 6).

La Constitución, como toda norma jurídica, puede interpretarse de forma distinta con el paso del tiempo pero hay unas bases que son su esencia, lo que el Tribunal Supremo de Canadá en la Opinión sobre la secesión de Quebec llamaba «estructura constitucional básica» (parágrafo. 50), y su interpretación hoy no dista mucho del espíritu con el que se redactaron en su momento. Tampoco cabe, como se hace en el referido escrito de la Generalitat, apelar sin más a los ejemplos de derecho comparado porque normalmente las circunstancias son distintas, las legislaciones diversas y por ello hay que estar a cada caso para ver si los modelos son extrapolables. Por último, no puede argumentarse, en fin, que «las consultas populares sirven de forma eminente a la protección de derechos individuales como la libertad ideológica y la libertad de expresión las consultas comportan, por tanto, el ejercicio de derechos individuales de los ciudadanos y sirven a los valores de libertad, igualdad y pluralismo político y al principio democrático» (2 pág. 10). Es cierto que el derecho recogido en el artículo 23.1 CE «se otorga a los ciudadanos en cuanto tales y, por consiguiente, a las personas individuales» (STC 51/1984, de 25 de abril. FJ 2) pero ya se ha señalado que la participación política directa expresa la voluntad general, y por tanto tiene un carácter inorgánico. En consecuencia, no puede identificarse solo con un derecho subjetivo individual, especialmente en los casos de referéndum. Su defensa por ello debe articularse poniendo el énfasis en el grupo, no en cada persona porque es expresión de la soberanía popular, no de la voluntad individual para lo que cada persona tiene reconocido, efectivamente, la libertad de expresión. La combinación de esos elementos personales y colectivos es precisamente una de las razones para enjuiciar críticamente la Ley que presentaba aspectos sobre los que debía discreparse como de alguna manera demuestra el fallo del Tribunal Constitucional declarando la inconstitucionalidad de la parte sustantiva de la Ley que ahora solo ampara la convocatoria de consultas sectoriales, nunca generales.

Title:

The Catalonia Law of popular consultations of 2014

Summary:

I. Introduction. II. Historical Previous Law Issues. III. Law Topic

(C) UNED. Revista de Derecho Politico 


\title{
Resumen:
}

La Ley Catalana de Consultas Populares de 2014 constituye un deseo de potenciar la participación ciudadana en la toma de decisiones políticas pero al tiempo era un intento de aprobar una norma que sirviera de marco jurídico para celebrar un verdadero referéndum sobre el futuro político de Cataluña, propósito evitado por el Tribunal Constitucional estableciendo que solo caben las consultas sectoriales y nunca las generales.

\section{Palabras clave:}

Consulta popular, referéndum, participación política, principio democrático, soberanía nacional.

\begin{abstract}
:
The Catalonia law of popular consultations of 2014, constitute a desire to enhance the citizen participation in political decision-making, but at the same time, it was an attempt to approve a lawe that would serve as the legal framework to hold a true referendum about the political future of Catalonia. This purpose was avoided by the Constitutional Court, stablishing that only sectoral and never general consultations are allowed.
\end{abstract}

\section{Key words:}

Popular consultations, referendum, political participation in decisions-making, democratic principle, national sovereignty. 